\title{
The Low Income Diet and Nutrition Survey. Findings: nutritional science
}

\author{
A. Tedstone \\ Food Standards Agency, 125 Kingsway, London WC2B 6NH, UK
}

The Low Income Diet and Nutrition Survey (LIDNS) ${ }^{(1)}$ was designed to assess the dietary habits and nutritional status of individuals living in materially-deprived households in the UK. Data were collected from a nationally-representative sample of 3728 individuals aged $\geq 2$ years between 2003 and 2005 using four $24 \mathrm{~h}$ recalls with estimated portion sizes, a blood sample and anthropometry. Nutrient intakes were compared with UK dietary recommendations ${ }^{(2)}$.

For adults aged 19-64 years the mean carbohydrate intakes were close to the recommendation of $\geq 50 \%$ food energy from carbohydrate (men $47.9 \%$, women 48.8\%), but non-milk extrinsic sugar (NMES) intakes exceeded the maximum recommendation of $11 \%$ (men $15.2 \%$, women $13.5 \%$ ). SFA intakes also exceeded the maximum recommendation of $11 \%$ food energy (men and women $13.4 \%$ ) and mean NSP intakes were low (men $12.8 \mathrm{~g}$, women $10.7 \mathrm{~g}$ ).

Mean vitamin and mineral intakes for adults (aged $\geq 19$ years) were close to or above the reference nutrient intake (RNI) with the exception of $\mathrm{Fe}$ for women $(79 \% \mathrm{RNI})$ and $\mathrm{Mg}$ and $\mathrm{K}$ for men and women $(84 \%$ and $72 \%$ respectively for $\mathrm{Mg}, 82 \%$ and $67 \%$ respectively for $\mathrm{K}$ ). Of the adults $>10 \%$ had intakes of vitamin $\mathrm{A}$, riboflavin, $\mathrm{Fe}, \mathrm{Mg}, \mathrm{K}$ and $\mathrm{Zn}$ below the lower RNI (LRNI).

Of the men aged $\geq 19$ years $25 \%$ had plasma vitamin $\mathrm{C}$ levels $<11 \mu \mathrm{mol} / \mathrm{l}$ and approximately one-fifth of adults had serum 25-hydroxyvitamin D levels $<25 \mathrm{nmol} / \mathrm{l}$.

Mean consumption of fruit and vegetables was 2.4 portions for men and 2.5 portions for women. Oily fish consumption was very low; only $15 \%$ of adults reported eating oily fish and the mean consumption of oily fish and oily-fish dishes overall was $34 \mathrm{~g} /$ week for men and $48 \mathrm{~g} /$ week for women.

Comparison with the general population sampled in the most-recent National Diet and Nutrition Survey ${ }^{(3)}$ showed similar patterns of nutrient intake for adults; however, mean NMES intakes were higher and NSP, fruit and vegetable, wholemeal bread and wholegrain and high-fibre breakfast cereal intakes were lower in LIDNS. For micronutrients the percentages with intakes below the LRNI tended to be slightly greater in LIDNS.

Of the men $62 \%$ and $63 \%$ of women were overweight or obese (BMI $>25 \mathrm{~kg} / \mathrm{m}^{2}$ ). Of the men $16 \%$ and $6 \%$ of women exceeded the weekly alcohol intake recommendation, but approximately one-fifth of adults reported that they did not drink at all. Of the men $45 \%$ and $40 \%$ of women smoked.

Overall reported diets were poor in the low-income population, but they are only slightly worse than those of the general population. The combination of these poor diets with obesity and other lifestyle factors that increase risk of chronic disease emphasises the need for continued public health efforts to improve diets and lifestyle across the UK population.

LIDNS was funded by the Food Standards Agency and conducted by the National Centre for Social Research with King's College London and University College London.

1. Nelson M, Erens B, Bates B, Church S \& Boshier T (editors) (2007) Low Income Diet and Nutrition Survey. London: The Stationery Office.

2. Department of Health (1991) Dietary Reference Values for Food Energy and Nutrients for the United Kingdom. London: H. M. Stationery Office.

3. Hoare J, Henderson L, Bates CJ, Prentice A, Birch M, Swan G \& Farron M (2004) National Diet and Nutrition Survey: Adults Aged 19 to 64 Years. vol. 5: Summary Report. London: The Stationery Office. 